\title{
1 Electrochemical jet-cell for the in-situ generation of hydrogen peroxide
}

Pérez, J.F.; Llanos, J.; Sáez, C.*; López, C.; Cañizares, P.; Rodrigo, M.A.

3 Chemical Engineering Department, Facultad de Ciencias y Tecnologías Químicas.

4 University of Castilla-La Mancha, Edificio Enrique Costa Novella. Av. Camilo José

$5 \quad$ Cela $\mathrm{n}^{\circ}$ 12, 13071 Ciudad Real, Spain

6 *Corresponding autor: Cristina.saez@uclm.es

\section{Abstract}

8 In this work, a proof of concept of a novel reactor design for the in-situ electrochemical 9 production of $\mathrm{H}_{2} \mathrm{O}_{2}$ from oxygen reduction reaction is presented for the first time. The 10 innovative design incorporates a venturi-based jet aerator to supply atmospheric oxygen 11 without additional energy consumption to a 3D flow-through modified carbon felt (CF) 12 cathode. Preliminary experiments confirmed that electro-generation of hydrogen 13 peroxide is possible in a system as the one proposed. Comparison with a flow-by cell with 14 a gas diffusion cathode under similar conditions revealed that current efficiency towards 15 hydrogen peroxide accumulation is even higher (72 vs $65 \%$ at 1 h) than in the case of the 16 conventional system. Jet aerator stands as a promising oxygen supply thanks to its 17 excellent performance and both low investment cost and energy consumption. 18 Considering all the above, the electrochemical jet cell stands as a rather promising design 19 for the efficient hydrogen peroxide electro-generation.

20 Keywords: hydrogen peroxide, gas diffusion electrode, jet electrochemical cell, carbon 21 felt 
Hydrogen peroxide is a widely used chemical in industries such as textile, pulp and paper bleaching, electronics, metallurgic or environmental applications as it is the case of water treatment, among others. Hydrogen peroxide is mostly manufactured on an industrial scale by means of the Riedl-Pfleiderer process (anthrahydroquinone autoxidation) since its implementation in 1940 by IG FarbenIndustrie [1]. Despite the fact that the yield is high and the process is commercially profitable, it does exhibit various disadvantages in environmental terms on account of its high energy consumption and large amounts of waste generated [2]. In addition, the product has to be transported over long distances from the production point to the end user. An alternative option for the generation of hydrogen peroxide in aqueous medium is the in-situ production from dissolved oxygen reduction reaction (ORR), according to Equation 1:

$$
\mathrm{O}_{2}+2 e^{-}+2 \mathrm{H}^{+} \rightarrow \mathrm{H}_{2} \mathrm{O}_{2}
$$

This way of production presents various advantages, e.g., ease of automation, mild reaction conditions, its applicability on a small scale and it being fully electricitypowered. Moreover, the electrochemical method avoids all the issues related to transport, storage and handling of this hazardous chemical [3].

The production rate and current efficiency is often limited by the low solubility of oxygen in water which is approximately $40 \mathrm{mg} \mathrm{dm}^{-3}$ (oxygen atmosphere) or $8 \mathrm{mg} \mathrm{dm}^{-3}$ (air atmosphere) at 1 atm, $25{ }^{\circ} \mathrm{C}$ and deionized water, depending basically on its partial pressure [4]. This problem has been addressed by substituting conventional electrodes for gas diffusion electrodes (GDEs) in which air or oxygen is directly supplied to the cathode without the need for it to be dissolved in the electrolyte [5]. However, $\mathrm{O}_{2} /$ air utilization efficiencies are extremely small, in the order of $<0.1 \%$ [6], resulting in a waste of energy and oversizing of compressors in the event of industrial application.

Because of this, an appropriate reactor design is of utmost importance. In the recent years, different authors have proposed novel electrochemical reactors based on flow-through electrodes because of the favorable mass transport rate [7-9]. In the particular case of electrochemical $\mathrm{H}_{2} \mathrm{O}_{2}$ reactors, it is important to ensure a continuous and sufficient supply of oxygen to the electrode, i.e., minimizing mass transport limitations to the minimum 
54 In this work, an innovative approach to electrochemical cell designing is presented for

55 the first time. The key feature is a jet aerator to supply oxygen to the system eliminating 56 the need for an external compressor. Also, a 3D flow-through modified carbon felt

57 cathode to achieve high space-time yield is used. With this novel approach to ORR reactor 58 design, higher $\mathrm{H}_{2} \mathrm{O}_{2}$ generation rate and lower energy consumption is intended compared 59 to conventional GDEs systems.

\section{$60 \quad$ 2. Materials and methods}

$61 \quad 2.1$ Electrolyte solution

62 All the experiments were performed in a Milli-Q water solution with a concentration of $6350 \mathrm{mM} \mathrm{Na}_{2} \mathrm{SO}_{4}$ as widely used in literature [10-12], supplied by Panreac and a total 64 electrolyte volume of $1 \mathrm{dm}^{3}$.

66 Two different experimental set-ups were used: the novel jet electrochemical cell 67 (henceforth referred to as jet cell) and a conventional flow-by cell with a gas diffusion 68 cathode (henceforth referred to as GDE cell). A conceptual picture of both cells is shown 69 in Figure 1.

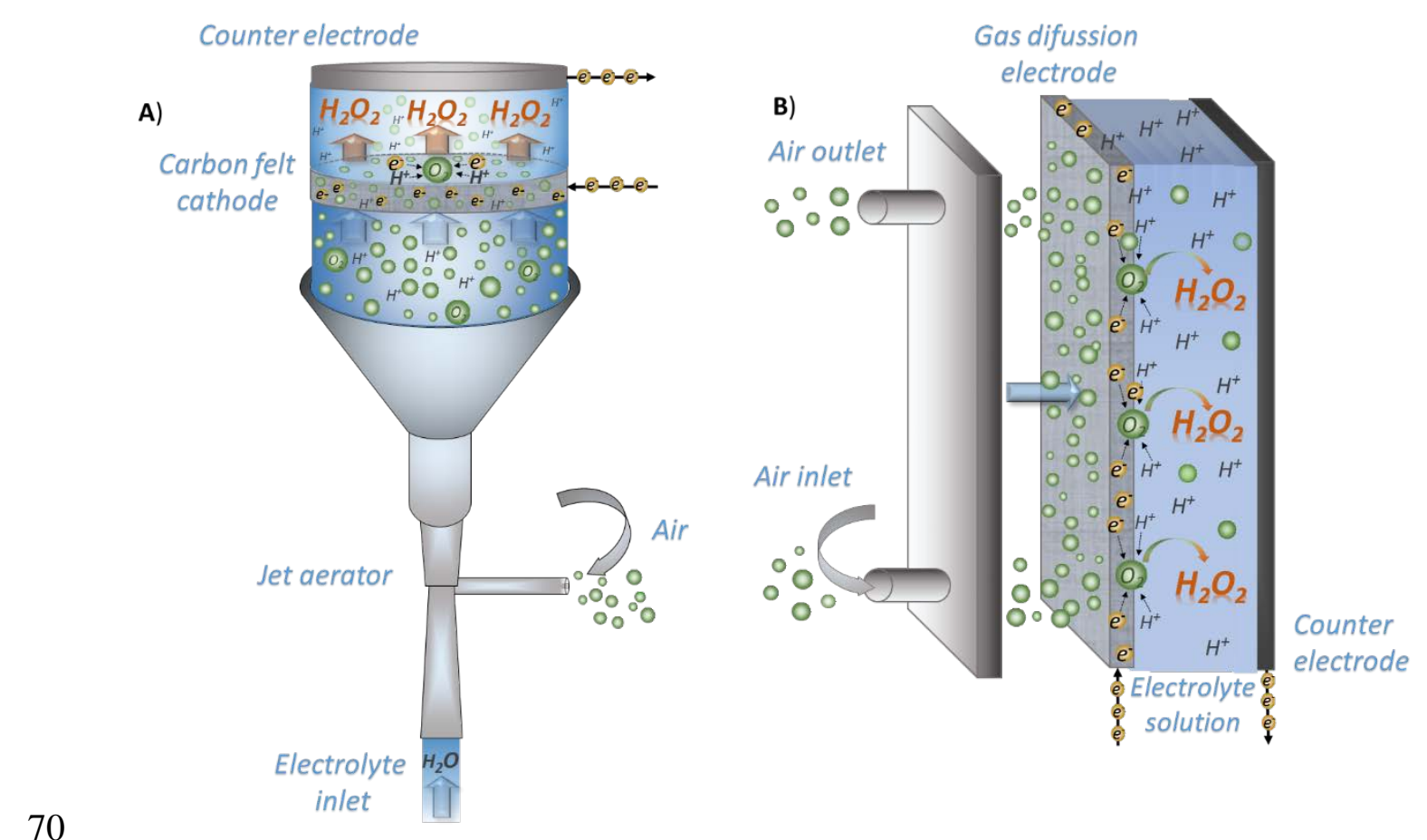

Figure 1. Conceptual picture of the electrochemical reactors. a) Jet cell b) GDE cell. 
72 In both electrochemical cells, a modified carbon felt (CF) electrode was used as the

73 cathode. The electrode was modified following a similar procedure to the one described 74 by $\mathrm{Yu}$ et al. [11] which mainly consists in immersing a carbon felt piece into an ink in an For hydrogen peroxide electro-generation, the oxygen supplied to the system must also ultrasonic bath. The composition of the ink was slightly modified with respect to Yu's and follows the receipt: $10 \mathrm{mg} / \mathrm{mL}-\mathrm{H}_{2} \mathrm{O}$ of carbon black (Vulcan ${ }^{\circledR}$ XC72R), $50 \mathrm{mg} / \mathrm{mL}$ $\mathrm{H}_{2} \mathrm{O}$ of polytetrafluoroethylene $\left(60 \%\right.$ Teflon ${ }^{\circledR}$ emulsion solution from ElectroChem, Inc.) and $20 \mathrm{~mL} / \mathrm{L}-\mathrm{H}_{2} \mathrm{O}$ of $n$-butanol. On its part, a titanium anode with active coating based on iridium oxides (Tianode, India) was used as counter electrode. Apart from the cell, each bench-scale installation is properly configured with auxiliary equipment (reservoir tanks, power supply, pump, rotameter, etc.)

\section{$2.3 \mathrm{H}_{2} \mathrm{O}_{2}$ measurement}

The hydrogen peroxide concentration was measured by the potassium titanium (IV) oxalate method [13] according to standard DIN 38 409, part 15, DEV-18. The titanium solution was supplied by Fluka and the absorbance was determined at $\lambda=407 \mathrm{~nm}$ by means of an Agilent 300 Cary series UV-Vis spectrophotometer.

\section{Theory}

The design of the novel electrochemical jet cell incorporates a key feature with the objective of enhancing efficiency of hydrogen peroxide electro-generation: a venturibased jet aerator as oxygen supply to a 3D flow-through modified carbon felt cathode with high space-time yield.

Regarding the former, a jet aerator is used to create a suction that entrains air into the water flow. This form of aeration does not need extra equipment, such as a compressor, representing a huge advantage with respect to conventional GDE systems because of the savings in investment and operating costs. Because of the high velocity in the throat of the jet aerator, the bubbles are broken into smaller pieces as a consequence of the high shear rates [14]. A fraction of the air flow sucked in the system is dissolved, saturating water in oxygen, while the rest of it remains undissolved in the form of air bubbles. This way, the water is supersaturated, i.e., it contains a concentration of oxygen higher than the one of the equilibrium described by Henry's law for a short period of time.

be in contact with electrons and protons at some point, according to Equation 1. The 
103 physical place where those three reagents coincide can be referred to as triple-contact point (TCP). An adequate cathode must provide a large surface area with many TCPs where reactants are supplied in sufficient quantities. Considering this, a graphite felt was selected as the cathode material since it possesses a large three-dimensional surface [10, 11]. Nevertheless, the $\mathrm{H}_{2} \mathrm{O}_{2}$ generation rate was reported to be low in bare graphite felt, requiring changes to increase its productivity. Yu et al. reported a simple method to modify this material, adding a carbonaceous powder (carbon black) and polytetrafluoroethylene (PTFE) as a hydrophobic agent [11]. By doing this, the surface area is increased [7] (and so do TCPs) and hydrophobicity facilitates gas diffusion into the inner parts of the porous structure favoring the oxygen supply to active sites. The last property is truly important since hydrogen peroxide electro-generation kinetic from ORR

114 is normally limited by the low concentration of oxygen in water [4] and, thus, being $\mathrm{O}_{2-}$

115 mass transfer controlled [15]. To minimize this limitation, the water flow is forced to pass

116 through the porous structure of the cathode, as shown in Figure 1.

117 These special hydrodynamic conditions are used to achieve a high space-time yield in

118 small concentrations of reactants by creating favorable mass transport conditions [7-9].

119 In fact, at similar linear empty tube flow velocities, the mass transport coefficient is 120 expected to be 5 to 6 times higher than for a plate electrode with parallel flow [16]. All 121 the aforementioned characteristics configure a promising reactor design for fast and efficient hydrogen peroxide electro-generation.

\section{Results and discussions}

124 A concept-proof experiment was conducted in the jet cell to demonstrate whether the 125 electro-generation of hydrogen peroxide is possible or not. This experiment was carried 126 out in $1 \mathrm{dm}^{-3} 0.05 \mathrm{M} \mathrm{Na}_{2} \mathrm{SO}_{4}$ medium at a current density of $50 \mathrm{~mA}$ per $\mathrm{cm}^{-3}$ of electrode 127 material. All the experiments were performed in triplicate to ensure reproducibility being 128 the value in Figure 2 the average of the three experiments. It shows a logarithmic trend 129 line, which is the typical dynamic response in non-divided electrochemical cells for the 130 electro-generation of $\mathrm{H}_{2} \mathrm{O}_{2}[5,17]$. High concentrations and current efficiencies of 450 131 (75\%), 725 (61\%) and 960 (51\%) $\mathrm{mg} \mathrm{H}_{2} \mathrm{O}_{2} \mathrm{dm}^{-3}$ were obtained after 1, 2 and 3 hours 132 of electrolysis, respectively. Therefore, the proof of concept is positive and it is 133 demonstrated that hydrogen peroxide can be generated in a flow-through modified carbon 134 felt cathode by using a jet aerator as oxygen supply. 


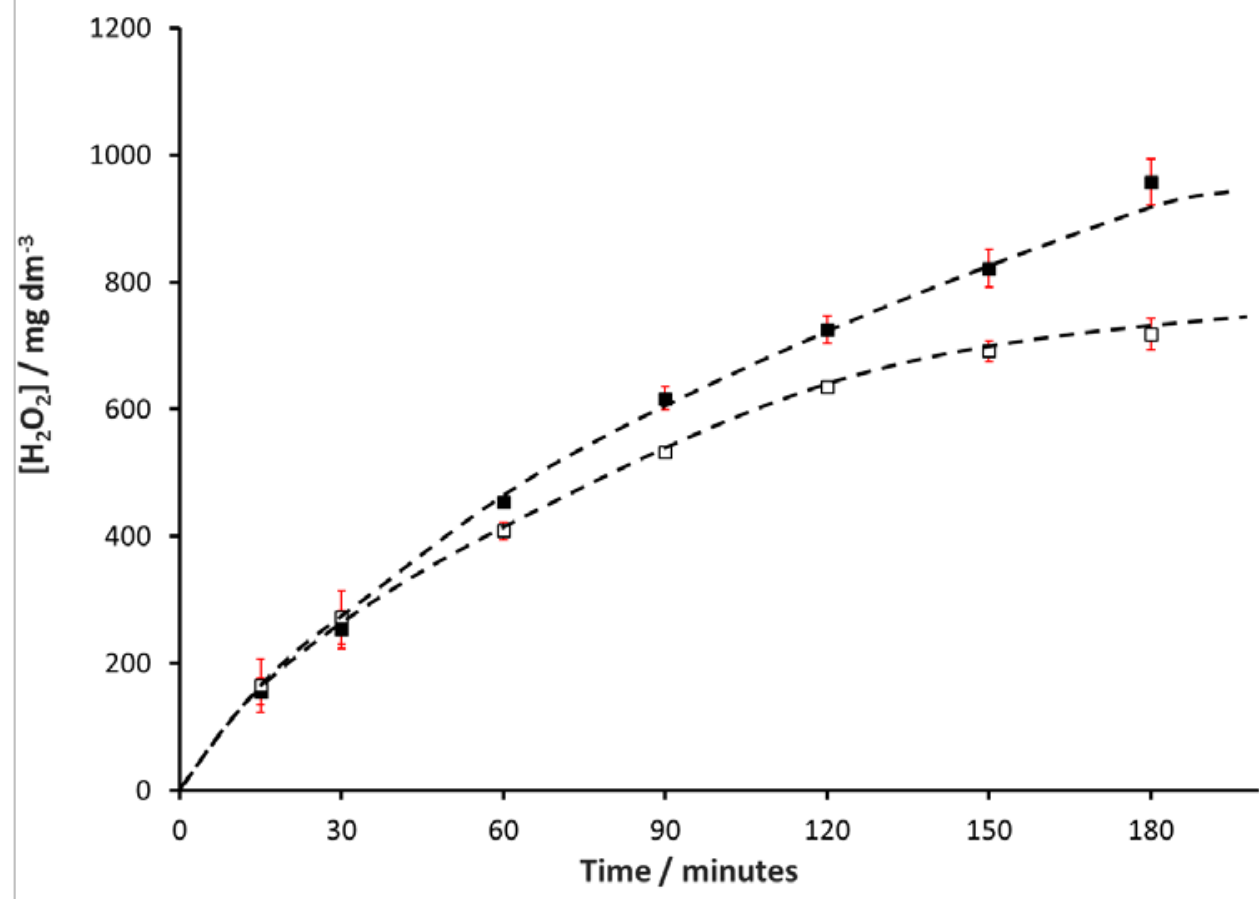

Figure 2. Concentration curves for hydrogen peroxide generation in the jet cell $\mathbf{\square}$ Jet cell $\square$ GDE cell. Current density $50 \mathrm{~mA} \mathrm{~cm}^{-3}$. Electrolytic medium: $0.05 \mathrm{M} \mathrm{Na}_{2} \mathrm{SO}_{4}$. Inter-electrode gap: $18 \mathrm{~mm}$

139 For comparative purposes, the hydrogen peroxide electro-generation was also performed

140 in a conventional flow-by cell using the same modified carbon felt electrode as a gas

141 diffusion electrode. To compare on equal terms, current density, anode material, 142 electrolytic medium, inter-electrode gap and ratio electrical charge/electrolyte volume 143 was kept constant in both cells. Considering Figure 2, it can be observed that the jet cell 144 accumulates a higher concentration of hydrogen peroxide than in the case of GDE cell. 145 The accumulation rate is the difference between the generation rate at the cathode (Eq. 1) 146 and the destruction rates, mainly as a consequence of a cathodic reduction (Eq. 2) and an 147 anodic oxidation (Eq. 3) [3, 18]. Destruction reactions leads to a severe decrease in current 148 efficiency since the applied electric charge not only is not used in producing hydrogen 149 peroxide molecules but, even worse, it decomposes the already existing ones. The current 150 efficiency can also be diminished by other parasitic reactions that do not involve hydrogen peroxide destruction such as hydrogen evolution (Eq. 4):

$$
\mathrm{H}_{2} \mathrm{O}_{2}+2 \mathrm{H}^{+}+2 e^{-} \rightarrow 2 \mathrm{H}_{2} \mathrm{O}(2)
$$

$$
\mathrm{H}_{2} \mathrm{O}_{2}-2 e^{-} \rightarrow \mathrm{O}_{2}+2 \mathrm{H}^{+}(3)
$$


156 At the beginning of the experiment, the destruction rates were low because the hydrogen

157 peroxide concentration was also low and the destruction may suffer from mass transfer

158 limitations. It is precisely at this time when the generation and accumulation rates are

159 quite similar and both reactors can be properly compared. According to Figure 2, the

160 tendency lines are overlapped in the first instants of the experiments indicating that the

161 generation is quite similar and the jet cell is as efficient as the conventional GDE cell for

162 the electro-generation of hydrogen peroxide.

163 The role of the jet aerator was further investigated in a non-stop experiment under three

164 different aeration conditions. Before starting, nitrogen was bubbled in the reservoir tank

165 for 10 minutes to strip all the oxygen and the valve controlling air flow into the system

166 through jet aerator was closed. Once the $\mathrm{O}_{2}$ concentration was set to zero, the experiment

167 began and the electrolysis was carried out for 30 minutes. At minute 30, nitrogen bubbling

168 was substituted by air sparging and the electrolysis continued for another 30 minutes.

169 Finally, air sparging was stopped and during the last 30 minutes of electrolysis, the oxygen

170 was supplied by using the jet aerator. The concentration-time curves obtained in this

171 experiment are shown in Figure 3. 


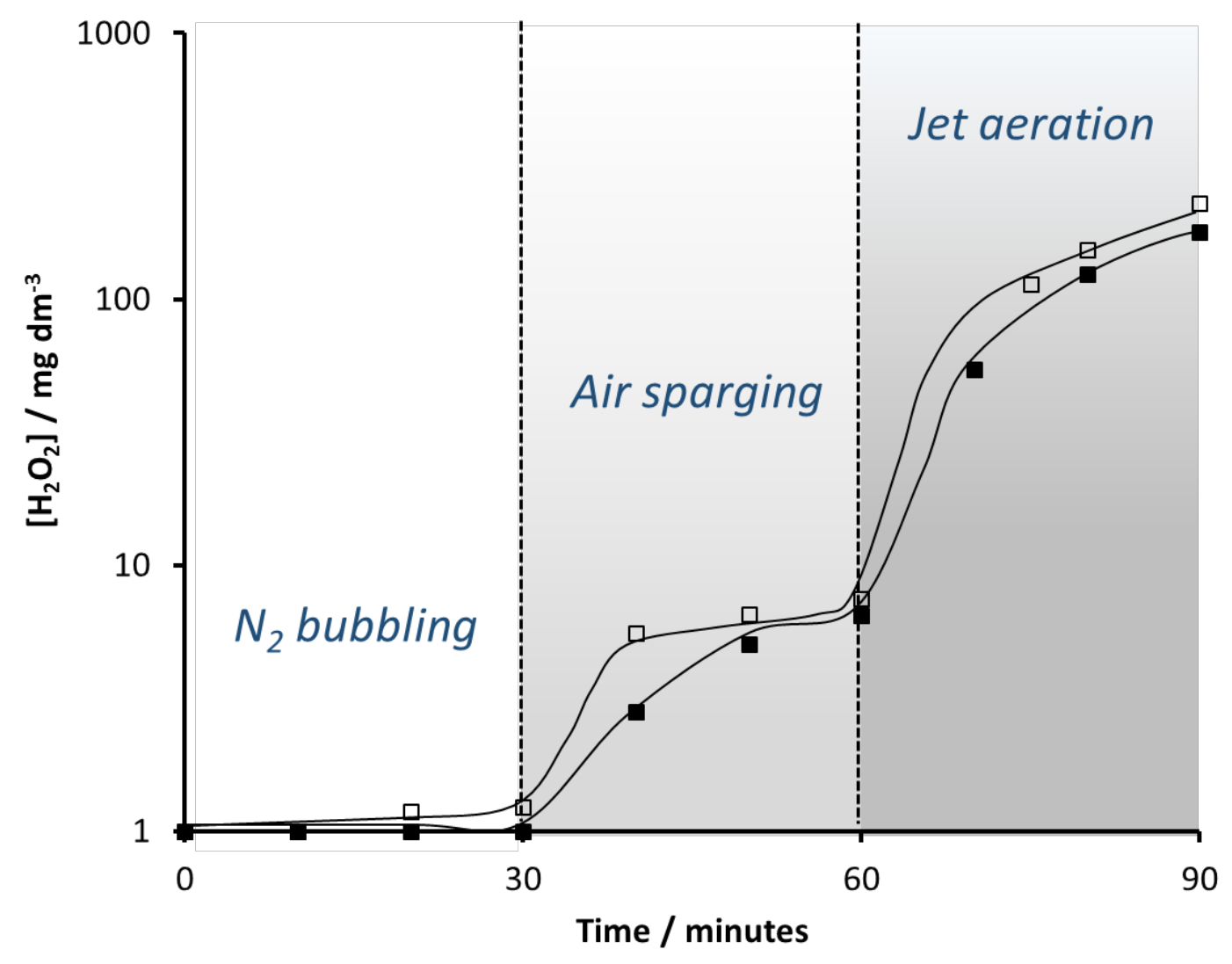

172

173 Figure 3. Hydrogen peroxide generation under different aeration conditions at different 174 current densities. $50 \mathrm{~mA} \mathrm{~cm}^{-3} \square 75 \mathrm{~mA} \mathrm{~cm}^{-3}$. Electrolytic medium: $1 \mathrm{dm}^{3} 0.05 \mathrm{M}$ $175 \mathrm{Na}_{2} \mathrm{SO}_{4}$.

176 The electrolysis under nitrogen bubbling led, as expected, to a very low concentration of 177 hydrogen peroxide since no oxygen is available for electro-reduction in the cathode. For 178 the next 30 minutes, hydrogen peroxide concentration was slightly higher but remains 179 very low, thus, obtaining poor current efficiencies, indicating that the dissolved oxygen 180 is not sufficient for an efficient hydrogen peroxide generation. It is not until the jet aerator 181 was used when hydrogen peroxide concentration takes off, especially in the case of the 182 higher current density. The cell potential fluctuates slightly $( \pm 0.2 \mathrm{~V}$ ) when bubbles (non183 conductive) are flowing through the cathode, without resulting in an operational problem.

184 This tremendous improvement in efficiency is associated with the formation of small to 185 medium air bubbles as a consequence of the turbulence generated in the throat of the 186 venture aerator [19] which may reach TCPs along the entire cathode surface by diffusing 187 through the pores thanks to the hydrophobicity of the PTFE added to modify the carbon 188 felt [20]. 
190 Hydrogen peroxide electro-generation in a new electrochemical reactor design based on

191 a jet aerator and a flow-through modified carbon felt (CF) cathode is demonstrated. The

192 comparison with a conventional GDE cell confirmed that this new approach is highly 193 efficient as demonstrated by its high current efficiency of 75, 61 and 51\% at 1, 2 and 3 h, 194 respectively. The jet aerator proved to be an excellent oxygen supply with a minimum 195 investment and energy costs. The electrochemical jet cell design is truly promising and 196 could mean a giant leap forward in the applicability of electro-generated hydrogen 197 peroxide as a green oxidant to environmental remediation in general, and water treatment 198 in particular.

\section{Acknowledgements}

200 Authors wish to express their gratitude to Junta de Comunidades de Castilla-La Mancha 201 for the funding through the project PEII-2014-039-P. 
210 [1] J.M. Campos-Martin, G. Blanco-Brieva, J.L.G. Fierro, Hydrogen Peroxide

211 Synthesis: An Outlook beyond the Anthraquinone Process, Angewandte Chemie

212 International Edition, 45 (2006) 6962-6984.

213 [2] A. Tiwari, S. Titinchi, Advanced Catalytic Materials, Wiley, 2015.

214 [3] E. Petrucci, A. Da Pozzo, L. Di Palma, On the ability to electrogenerate hydrogen

215 peroxide and to regenerate ferrous ions of three selected carbon-based cathodes for

216 electro-Fenton processes, Chemical Engineering Journal, 283 (2016) 750-758.

217 [4] O. Scialdone, A. Galia, C. Gattuso, S. Sabatino, B. Schiavo, Effect of air pressure on

218 the electro-generation of $\mathrm{H} 2 \mathrm{O} 2$ and the abatement of organic pollutants in water by

219 electro-Fenton process, Electrochimica Acta, 182 (2015) 775-780.

220 [5] R.M. Reis, A.A.G.F. Beati, R.S. Rocha, M.H.M.T. Assumpção, M.C. Santos, R.

221 Bertazzoli, M.R.V. Lanza, Use of Gas Diffusion Electrode for the In Situ Generation of

222 Hydrogen Peroxide in an Electrochemical Flow-By Reactor, Industrial \& Engineering

223 Chemistry Research, 51 (2012) 649-654.

224 [6] F. Yu, M. Zhou, L. Zhou, R. Peng, A Novel Electro-Fenton Process with H2O2 Generation in a Rotating Disk Reactor for Organic Pollutant Degradation, Environmental Science \& Technology Letters, 1 (2014) 320-324.

[7] G. Ren, M. Zhou, M. Liu, L. Ma, H. Yang, A novel vertical-flow electro-Fenton reactor for organic wastewater treatment, Chemical Engineering Journal, 298 (2016) 5567.

230 [8] L. Ma, M. Zhou, G. Ren, W. Yang, L. Liang, A highly energy-efficient flowthrough electro-Fenton process for organic pollutants degradation, Electrochimica Acta, 200 (2016) 222-230.

[9] G. Gao, Q. Zhang, Z. Hao, C.D. Vecitis, Carbon nanotube membrane stack for flowthrough sequential regenerative electro-Fenton, Environmental Science and Technology, 49 (2015) 2375-2383.

236 [10] M. Zhou, Q. Tan, Q. Wang, Y. Jiao, N. Oturan, M.A. Oturan, Degradation of

237 organics in reverse osmosis concentrate by electro-Fenton process, Journal of

238 Hazardous Materials, 215-216 (2012) 287-293.

239 [11] F. Yu, M. Zhou, X. Yu, Cost-effective electro-Fenton using modified graphite felt

240 that dramatically enhanced on $\mathrm{H} 2 \mathrm{O} 2$ electro-generation without external aeration,

241 Electrochimica Acta, 163 (2015) 182-189.

242 [12] J. Miao, H. Zhu, Y. Tang, Y. Chen, P. Wan, Graphite felt electrochemically modified in $\mathrm{H} 2 \mathrm{SO} 4$ solution used as a cathode to produce $\mathrm{H} 2 \mathrm{O} 2$ for pre-oxidation of drinking water, Chemical Engineering Journal, 250 (2014) 312-318.

[13] G. Eisenberg, Colorimetric Determination of Hydrogen Peroxide, Industrial \& Engineering Chemistry Analytical Edition, 15 (1943) 327-328.

247 [14] T.R. Cumby, A review of slurry aeration 3. Performance of aerators, Journal of

248 Agricultural Engineering Research, 36 (1987) 175-206.

249 [15] H. Luo, C. Li, C. Wu, W. Zheng, X. Dong, Electrochemical degradation of phenol

250 by in situ electro-generated and electro-activated hydrogen peroxide using an improved gas diffusion cathode, Electrochimica Acta, 186 (2015) 486-493.

[16] E. Heitz, G. Kreysa, Principles of Electrochemical Engineering: Extended Version of a DECHEMA Experimental Course, VCH, 1986.

254 [17] Y. Sheng, S. Song, X. Wang, L. Song, C. Wang, H. Sun, X. Niu, Electrogeneration of hydrogen peroxide on a novel highly effective acetylene black-PTFE cathode with PTFE film, Electrochimica Acta, 56 (2011) 8651-8656. 
257 [18] M. Panizza, G. Cerisola, Electrochemical generation of H2O2 in low ionic strength 258 media on gas diffusion cathode fed with air, Electrochimica Acta, 54 (2008) 876-878.

259 [19] J.L. Adrianus van Haandel, Handbook Biological Waste Water Treatment - Design 260 and Optimisation of Activated Sludge Systems, Quist, 2007.

261 [20] Y. Sheng, Y. Zhao, X. Wang, R. Wang, T. Tang, Electrogeneration of H2O2 on a 262 composite acetylene black-PTFE cathode consisting of a sheet active core and a 263 dampproof coating, Electrochimica Acta, 133 (2014) 414-421. 